\title{
TOXICITY OF DIFFERENT PLANT EXTRACTS AND GREEN SILVER NANOPARTICLES AGAINST PLUTELLA XYLOSTELLA (LEPIDOPTERA: PLUTELLIDAE)
}

\author{
Farhad Ali' ${ }^{1}$, Muhammad Tariq ${ }^{1}$, Farid Asif Shaheen ${ }^{1}$, Zia-ur-Rehman Mashwani' ${ }^{2}$, Tayyaba Zainab ${ }^{3}$, Asim Gulzar ${ }^{1}$ \\ ${ }^{1}$ Department of Entomology, Pir Mehr Ali Shah Arid Agriculture University Rawalpindi, Pakistan. \\ ${ }^{1}$ Department of Botany, Pir Mehr Ali Shah Arid Agriculture University Rawalpindi, Pakistan. \\ ${ }^{1}$ University Institute of Biochemistry and Biotechnology, Pir Mehr Ali Shah Arid Agriculture University Rawalpindi, Pakistan.
}

\section{AR T I C L E I N F O}

\section{Article history}

Received: June 28, 2019

Revised: September 13, 2019

Accepted: December 15, 2019

\section{Keywords}

Silver nanoparticles

Plant extracts

Plutella xylostella

Mortality
A B S T R A C T

Diamondback moth, Plutella xylostella (Lepidoptera: Plutellidae) is one of the most notorious and cosmopolitan insect pests of brassica crops around the world. P. xylostella may cause $90 \%$ yield losses in brassica crops. Various control measures have been adopted to manage this pest; however, the most effective control method is the use of synthetic chemical insecticides. Overuse of insecticides have many adverse effects including insecticide resistance, hazardous to environment, long persistency, interference with food chain. There is an urgent need for alternative control measures which should be effective, environmental friendly and economically safer. Bio-pesticides include plant extracts and green synthesized nano-based insecticides are among the feasible alternative measures which can be useful for the management of P. xylostella. Less work has been carried out on the use of green synthesized plant products against P. xylostella. Therefore, the current study was planned to evaluate the toxicity of plant extracts and green synthesized nano-based plant products against $P$. xylostella. Eight plants extracts (neem, bakain, bitter gourd, clove, eucalyptus, dathura, garlic and ginger) and their nano-based products (green synthesis silver nanoparticles) were applied in different concentrations against $3^{\text {rd }}$ larval instars of P. xylostella. Mortality were recorded after 24, 48 and 72 hours of application of treatments. Corrected mortality was calculated using Abbot's formula and $\mathrm{LC}_{50}$ values were calculated. All the plants extract had great potential to kill the maximum population of diamondback moth at high concentration. All these plants extract gave more than $80 \%$ mortality which was at the rate of 23,24, 20 and $30 \mathrm{mg} / \mathrm{ml}$ respectively after 72 hour interval. The present study indicated that the botanical insecticides have good toxic effect against the $3^{\text {rd }}$ instar larvae of diamondback moth.

Corresponding Author: Farhad Ali

Email: farhadali415@gmail.com

(C) 2019 EScience Press. All rights reserved.

\section{INTRODUCTION}

Diamondback moth, Plutella xylostella (Lepidoptera; Plutellidae) is a notorious pest of brassica crops and is distributed around the globe. P. xylostella is a major pest of cauliflower and other brassica crops and damage the crops throughout the year due to availability of many 
host plants (Li et al., 2016). This pest has attained the status of most extensively distributed insect pest among all the Lepidoptera insect pests (Grzywacz et al., 2010). The diamond back moth has this exceptional pest status due to the diversity and abundance of its host plants ( $\mathrm{Li}$ et al., 2016). Another important factor is its high reproductive potential and studies have shown more than 20 generations per year for $P$. xylostella (Shelton and Nault, 2004). This pest has the potential to cause $90 \%$ yield losses and the annual damage may reach approximately \$ 4-5 billion per year. It is estimated that the global annual management cost for this pest is over US $\$ 1.0$ billion (Furlong et al., 2013).

Various control measures have been adopted to manage P. xylostella however, the most effective control method is the use of synthetic chemical insecticides ( $\mathrm{Li}$ et al., 2016). The intensive application of synthetic insecticides against $P$. xylostella resulted in insecticide resistance to all groups of synthetic insecticides (Sayyed et al., 2004). The overuse of insecticides have many adverse effects including insecticide resistance, hazardousness to environment, long persistency, interference with food chain and negative impact on non-target organisms ( $\mathrm{Li}$ et al., 2016).

To overcome above mentioned problems, use of biopesticides derived from plants with potential insecticidal activity is one of the available options. Biopesticides are considered valid alternative control measures to conventional synthetic insecticides against P. xylostella. Biopesticides include plant extracts and green synthesized nano-based insecticides are among these measures which can be useful for the management of P. xylostella (Patil et al., 2017). The use of natural insecticides extracted from plants have shown considerable success against $P$. xylostella and these plant extracts are environmentally suitable and development of resistance against them has not yet been reported.

Various plant extracts have been used in many countries throughout the world for the management of insect pests including P. xylostella (Patil et al., 2017). These plant extracts have many bioactive compounds which act as insecticides in terms of anti-feedants, repellents, fecundity reduction and respiration inhibiting agent (ElBokl, 2016). For example, Azadirachta indica, Zingiber officinale, Momordica charantia, Melia azedarach, Allium sativum and over 2000 plant species have insecticidal properties (Ahmad et al., 2012; Ahmed et al., 1984; Bullangpoti et al., 2012; Isman, 1999; Jacobson, 1989; Li et al., 2001; Loc et al., 2014; Rembold, 1989; Sarker et al., 2007; Schmutterer, 1990).

Green synthesized nanoparticles are one of the most effective and environmental friendly biopesticides (Benelli, 2016). Recent study has shown that green synthesized silver nanoparticles are most reliable biopesticides (Benelli, 2016) which can be used as alternative control measure against $P$. xylostella. As less work has been carried out on the use of green synthesized plant products against P.xylostella, therefore, current study has been planned to evaluate the toxicity of eight plant extracts and green synthesized silver nanoparticles of these plant products against $P$. xylostella.

\section{MATERIAL AND METHODS}

In the current study, different parts of eight plants were used to prepare plant extracts. The details of these plant parts are given in Table 1. Silver nitrate (AgNO3) and distilled water was used to prepare the silver nanoparticles and ethanol and above plants materials were used to prepare the extracts of plants.

Preparation of plant extracts: The above plant material was washed to remove dust and impurities. All these plant materials were dried under the shade for about three weeks. The dried plant materials were crushed into fine powder with the help of electric grinder. The powder of each plant extract was sieved through 20 mesh size sieve to obtain a favorable size range.

The botanical extracts were prepared by mixing $100 \mathrm{~g}$ powder with $500 \mathrm{ml}$ ethanol of each plant. The solution was stirred with a magnetic stirrer. The suspension was filtered through Whatman No. 1 filter paper and the flask was covered with aluminum paper. The plant extract was shaken manually twice a day. The ethanol solvent was removed by rotary evaporator and dry crude extract of plant material was collected. Same procedure was used for each plant material. There were eight treatments.

Synthesis of silver nanoparticles: Ten grams extract powder of each plant material were used for the preparation of green synthesis silver nanoparticles by adding in $250 \mathrm{ml}$ double distill water in flask. The mixture was boiled on hot plate for 5 minutes. The extract was filtered using Whatman filter paper No.1. The filtrate was mixed with $1 \mathrm{mM}$ of silver nitrate (AgNO3) solution and the solution was placed on hot plate for 10 minutes until its colour became brown 
which confirmed the formation of AgNPs (Parashar et al., 2009).

Rearing of Plutella xylostella larvae: The larvae of $P$. xylostella were collected from the cultivated field of cauliflower. They were kept in plastic jars at $25 \pm 2^{\circ} \mathrm{C}$ with $70 \pm 5 \%$ relative humidity and a photoperiod of $12 \mathrm{~L}: 12 \mathrm{D}$ in the Insect Molecular Laboratory, Department of Entomology, University Arid Agriculture Rawalpindi. The mouths of cages were covered by muslin cloth for providing food and management. Fresh cauliflower leaves were provided as food for the larvae and were replaced daily. The adults were fed by $10 \%$ sugar solution soaked in cotton wick as a food. A fresh cauliflower leaf was kept in each jar for oviposition. The insects were reared under these conditions and used for bioassay.

Characterization of green silver nanoparticles: Green silver nanoparticles were checked for the corresponding and absorbance wavelengths by using UV-Vis spectrophotometer at the Alpha Genomics Laboratory, Islamabad (Figure 1).

Table 1. Detail of plant parts of different plants used in the study.

\begin{tabular}{clll}
\hline Sr. No. & Plant & Scientific Name & Part used \\
\hline 1 & Eucalyptus & Eucalyptus camaldulensis & Leaves \\
2 & Neem & Azadirachta indica & Leaves \\
3 & Bakain & Melia azedarach & Leaves \\
4 & Datura & Datura stramonium & Fruits \\
5 & Dried clove & Syzygium aromaticum & Fruits \\
6 & Bitter gourd & Momordica charantia & Fruits \\
7 & Garlic & Allium sativum & Fruits \\
8 & Ginger & Zingiber officinale & underground stem fruit \\
\hline
\end{tabular}
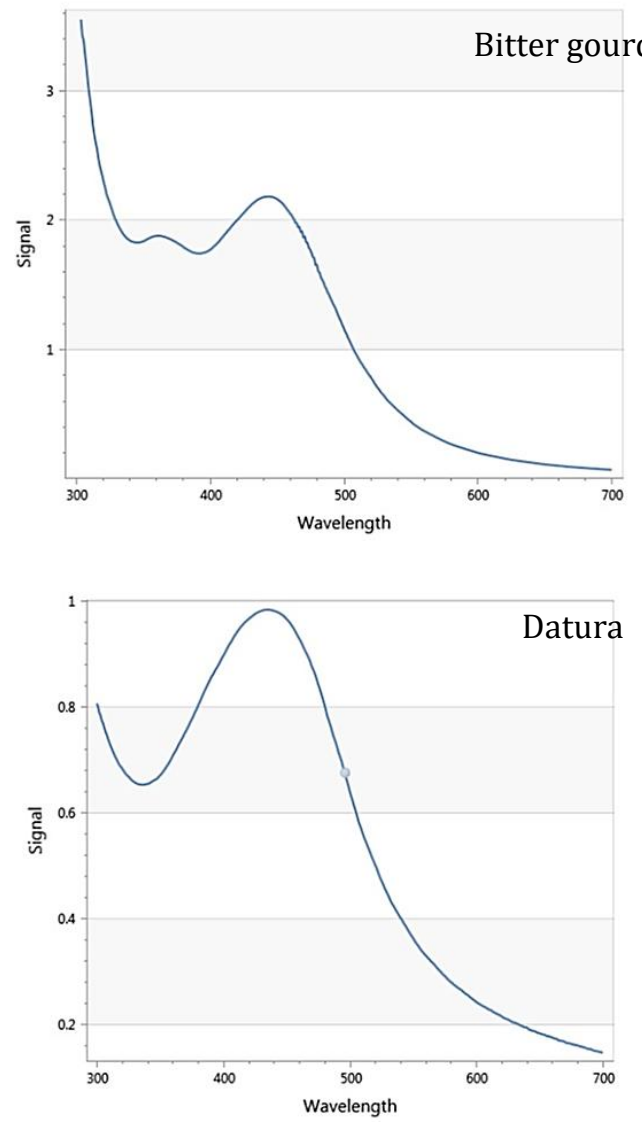
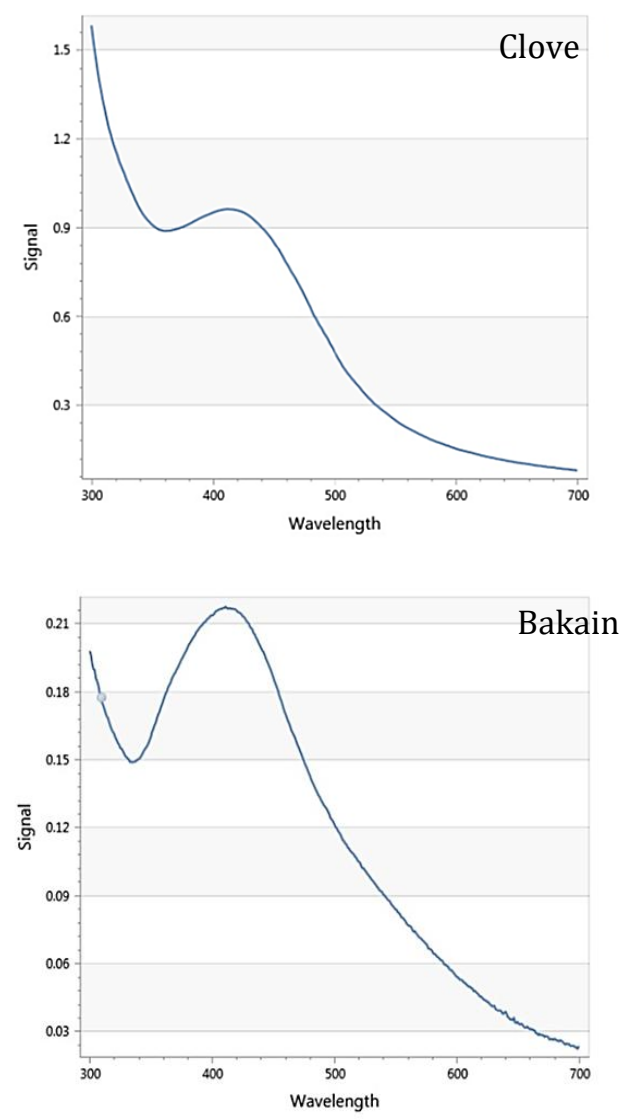

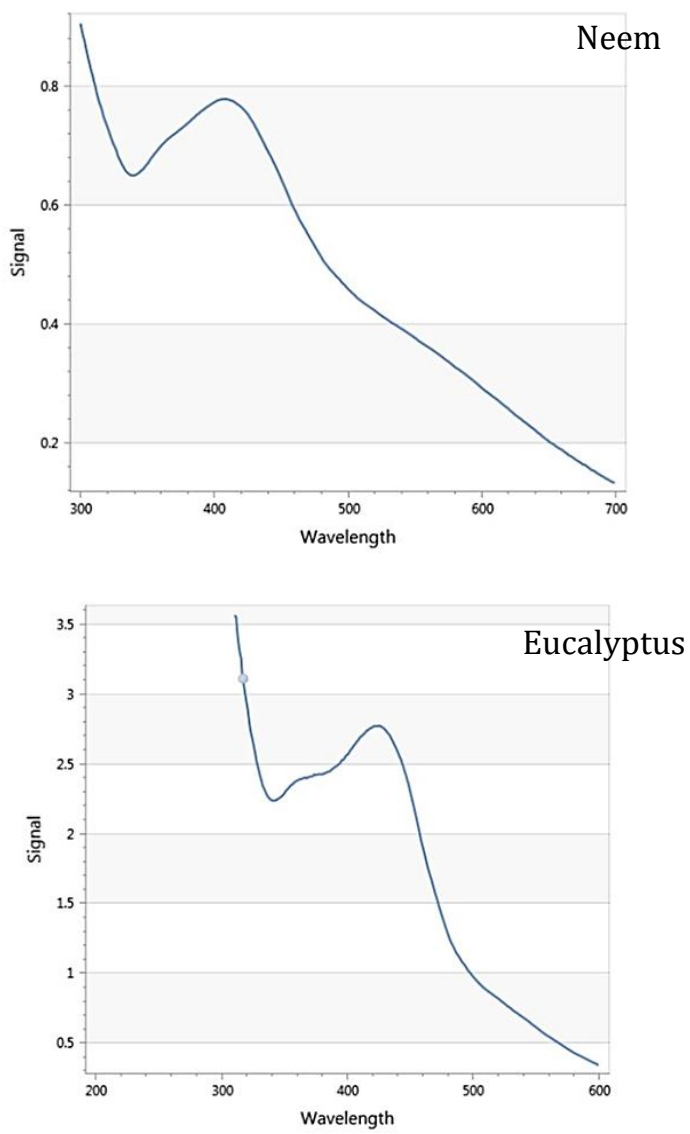
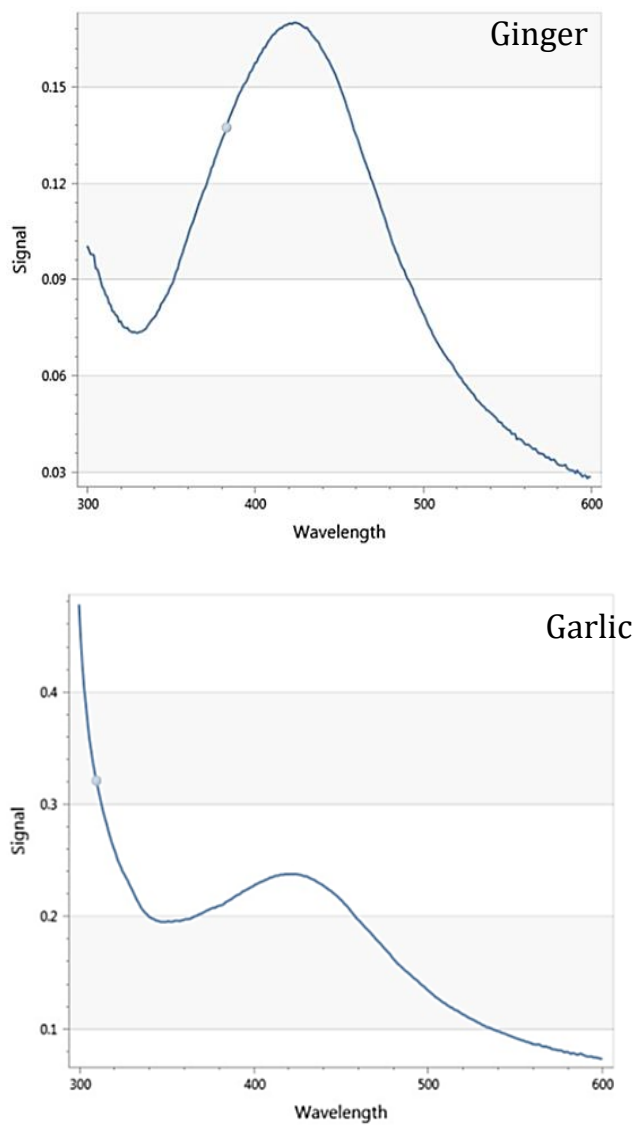

Figure1. UV characterization of silver nanoparticles of different plants.

\section{Experimental bioassay}

Larvicidal toxicity of plant extracts: The toxicity of eight treatments was tested against $3^{\text {rd }}$ larval instar of $P$. xylostella. Twenty five larvae of $P$. xylostella were used in single concentration. Five concentrations for each treatment with five replications were used in each bioassay. All bioassays were conducted in Insect Molecular Laboratory, Department of Entomology, University of Arid Agriculture Rawalpindi under control condition. Mortality data were recorded after 24, 48 and 72 hours after application of each treatments.

Larvicidal toxicity of green synthesis Ag nanoparticles: The above mentioned green synthesized silver nanoparticles of eight plant extracts were used against $3^{\text {rd }}$ larval instar of $P$. xylostella to observe the toxicity of green silver nanoparticles as mentioned above.

Statistical analysis: Mortality data for each treatment were recorded and corrected mortalities were calculated using Abbot's formula. $\mathrm{LC}_{50}$ values were calculated from probit analysis software. Statistical Package for Social Sciences version 16 was used for the standard error mean analysis.

\section{RESULTS}

Larvicidal potential of ginger (Zingiber officinale) against $3^{\text {rd }}$ instar larvae of Plutella xylostella: The ethanol plant extract of $Z$. officiale showed $72 \%$ mortality at the highest concentration of $23 \mathrm{mg} / \mathrm{ml}$ against the $3^{\text {rd }}$ instar larvae of $P$. xylostella. Ethanol extracts at the lowest concentration of $1.4375 \mathrm{mg} / \mathrm{ml}$ showed only $20 \%$ mortality when exposed for 24 hours. For 48 hours, $76 \%$ mortality was observed whereas the percentage mortality of the lowest concentration only increased up to $24 \%$. The final values at the 72 hours interval for the highest and lowest concentrations were $84 \%$ and $32 \%$ respectively. The results were obtained based on the Probit Analysis between the concentrations of plant extract against the $3^{\text {rd }}$ instar larvae of $P$. xylostella for the entire experiment. For 24, 48, and 72 hours, the $\mathrm{LC}_{50}$ values obtained were $12.701,8.898$, and $5.704 \mathrm{mg} / \mathrm{ml}$ respectively (Table 2 ).

The ginger enhanced silver nanoparticles showed $76 \%$ mortality at the highest concentration of $2.3 \mathrm{mg} / \mathrm{ml}$ 
against the $3^{\text {rd }}$ instar of $P$. xylostella. Silver nanoparticles at the lowest concentration of $0.014375 \mathrm{mg} / \mathrm{ml}$ showed only $24 \%$ mortality when exposed for 24 hours. For 48 hours, $84 \%$ mortality was observed whereas the percentage mortality of the lowest concentration only increased up to $28 \%$. The final values at the 72 hours interval for the highest and lowest concentrations were $88 \%$ and $36 \%$ respectively. For 24,48 , and 72 hours, the $\mathrm{LC}_{50}$ values obtained were $1.024,0.716$, and 0.382 $(\mathrm{mg} / \mathrm{ml})$ respectively (Table 3$)$.

Table 2. $\mathrm{LC}_{50}$ values and fiducial limit of different plant extracts for different time intervals against $3^{\text {rd }}$ instar larvae of P. xylostella.

\begin{tabular}{cccc}
\hline Plant extract & \multicolumn{3}{c}{$\mathrm{LC}_{50}(\mathrm{mg} / \mathrm{ml})$ with fiducial limit } \\
\cline { 2 - 4 } & 24 hours & 48 hours & 72 hours \\
\hline Ginger & 12.701 & 9.898 & 5.704 \\
& $(8.899-18.604)$ & $(4.652-13.429)$ & $(-0.622-9.340)$ \\
Neem & 9.368 & 7.248 & 4.331 \\
& $(4.120-14.975)$ & $(1.136-12.002)$ & $(-2.461-8.234)$ \\
Clove & 14.123 & 9.496 & 6.567 \\
& $(9.222-21.488)$ & $(4.278-14.372)$ & $(0.315-10.901)$ \\
Datura & 9.432 & 6.697 & 2.990 \\
& $(4.919-16.170)$ & $(1.561-11.142)$ & $(-5.698-6.882)$ \\
Bakain & 17.654 & 11.857 & 6.746 \\
& $(9.856-27.599)$ & $(-0.046-20.557)$ & $(-6.528-13.715)$ \\
Bitter Gourd & 15.095 & 11.715 & 8.683 \\
& $(9.031-24.781)$ & $(4.971-18.935)$ & $(1.877-13.998)$ \\
Eucalyptus & 16.126 & 11.172 & 6.542 \\
& $(9.442-29.041)$ & $(3.746-18.559)$ & $(-8.175-12.758)$ \\
Garlic & 12.135 & 9.237 & 6.689 \\
& $(7.977-18.822)$ & $(5.250-13.682)$ & $(1.632-10.684)$ \\
\hline
\end{tabular}

Table 3. $\mathrm{LC}_{50}$ values and fiducial limit of different plants silver nanoparticles for different time intervals against $3^{\text {rd }}$ instar larvae of $P$. xylostella.

\begin{tabular}{cccc}
\hline \multirow{2}{*}{$\begin{array}{c}\text { Plant silver } \\
\text { nanoparticles }\end{array}$} & \multicolumn{3}{c}{$\mathrm{LC}_{50}(\mathrm{mg} / \mathrm{ml})$ with fiducial limit } \\
\cline { 2 - 4 } Ginger & 24 hours & 48 hours & 72 hours \\
& 1.024 & 0.716 & 0.382 \\
Neem & $(0.656-1.484)$ & $0.331-1.062)$ & $(-0.185-0.7180)$ \\
& 0.948 & 0.660 & 0.611 \\
Clove & $(0.481-1.446)$ & $0.116-1.070)$ & $(-0.203-0.628)$ \\
& 1.358 & 0.856 & 0.517 \\
Datura & $(0.869-2.062)$ & $(0.286-1.339)$ & $(-0.224-0.955)$ \\
& 0.851 & 0.609 & 0.337 \\
Bakain & $(0.438-1.354)$ & $0.155-0.978)$ & $(-0.326-0.686)$ \\
& 1.565 & 1.029 & 0.532 \\
Bitter Gourd & $(0.583-2.624)$ & $(-0.347-1.877)$ & $(-0.753-1.182)$ \\
& 1.324 & 0.951 & 0.639 \\
Eucalyptus & $(0.739-2.070)$ & $(0.163-1.590)$ & $(-0.129-1.125)$ \\
& 1.367 & 0.951 & 0.514 \\
Garlic & $(0.620-2.451)$ & $(0.163-1.590)$ & $(-1.454-0.971)$ \\
& 1.156 & 0.902 & 0.729 \\
& $(0.720-1.805)$ & $(0.481-1.354)$ & $(0.205-1.162)$ \\
\hline
\end{tabular}


Larvicidal potential of neem (Azadirachta indica) against $3^{\text {rd }}$ instar larvae of Plutella xylostella: At 24 hours, the ethanol extract of neem plant showed $72 \%$ and $20 \%$ mortalities at higher and lower concentrations of $24 \mathrm{mg} / \mathrm{ml}$ and $1.5 \mathrm{mg} / \mathrm{ml}$ respectively. For 48 hours, the ethanolic plant extract of neem showed $76 \%$ mortality at higher limit and $32 \%$ at lower limit of plant extract. The final data obtained at 72 hours shoed the $84 \%$ mortality at higher concentrations and $36 \%$ at lower concentrations. The $\mathrm{LC}_{50}$ values calculated from probit and logit analysis software which are different for different time intervals 24, 48, 72 hours were 9.368, 7.248 and $4.33 \mathrm{mg} / \mathrm{ml}$ respectively (Table 2 ).

The green silver nanoparticles of neem plant gave $76 \%$ mortality at the highest concentration of $2.4 \mathrm{mg} / \mathrm{ml}$ against the $3^{\text {rd }}$ instar larvae of $P$. xylostella. Silver nanoparticles at lowest concentration of $0.15 \mathrm{mg} / \mathrm{ml}$ showed only $28 \%$ mortality when exposed for 24 hours. For 48 hours, $80 \%$ mortality was observed whereas the percentage mortality of the lowest limit of concentration increased only up to $32 \%$. The final values were recorded at the 72 hours interval for higher and lower limits of concentration were $92 \%$ and $36 \%$ respectively. Based on the probit analysis between the concentrations of plant extract against the $3^{\text {rd }}$ instar larvae of $P$. xylostella for the entire experiment for 24,48 , and 72 hours, the $\mathrm{LC}_{50}$ values obtained were $0.948,0.660$ and $0.611 \mathrm{mg} / \mathrm{ml}$ respectively (Table 3).

Larvicidal potential of clove (Syzygium aromaticum) against $3^{\text {rd }}$ instar larvae of Plutella xylostella: The application of clove plant extract of $28 \mathrm{mg} / \mathrm{ml}$ concentration showed the highest mortality of $72 \%$ while $1.75 \mathrm{mg} / \mathrm{ml}$ concentration showed the lowest mortality $20 \%$ after 24 hours. The treated values observed after 48 hours gave the maximum of $80 \%$ mortality at higher concentration and minimum $24 \%$ mortality at lower concentration. After 72 hours, the final mortality values increased up to $84 \%$ and $28 \%$. The $\mathrm{LC}_{50}$ values observed after 24,48 and 72 hours were $14.123,9.496$ and 6.567 respectively which were calculated from the probit and logit analysis software (Table 3).

The silver nanoparticles of clove were applied on the $3^{\text {rd }}$ larval instar of P. xylostella gave $76 \%$ mortality and $24 \%$ mortality at $2.8 \mathrm{mg} / \mathrm{ml}$ and $0.175 \mathrm{mg} / \mathrm{ml}$ after 24 hours. For 48 hours, the mortality values were $84 \%$ and $32 \%$ respectively. The final values which obtained after 72 hours were $88 \%$ and $36 \%$ at higher and lower limit of clove silver nanoparticles against $3^{\text {rd }}$ instar larvae of $P$. xylostella. The final values of $\mathrm{LC}_{50}$ for different time intervale were 1.358, 0.856 and 0.517 (in $\mathrm{mg} / \mathrm{ml}$ ) respectively (Table 3 ).

Larvicidal potential of datura (Datura stramonium) against $3^{\text {rd }}$ instar larvae of Plutella xylostella: In 20 $\mathrm{mg} / \mathrm{ml}$ concentration after 24 hours, the larvae of $P$. xylostella treated with datura plant extract was recorded the highest mortality of $68 \%$ at $20 \mathrm{mg} / \mathrm{ml}$ and 1.25 $\mathrm{mg} / \mathrm{ml}$ at lower value of concentration gave the minimum mortality of $24 \%$. The maximum and minimum mortalities of $76 \%$ and $28 \%$ were observed after 48 hours' time interval and larvae of $P$. xylostella were treated with datura plant extract and the mortality data was recorded after 72 hours gave the highest mortality value of $80 \%$ and $36 \%$. For 24,48 and 72 hours, the $\mathrm{LC}_{50}$ values of $9.432,6.697$ and 2.990 were obtained from the probit and logit analysis software (Table 2).

The larvae of $P$. xylostella treated with the green silver nanoparticles of datura at higher concentration of 2 $\mathrm{mg} / \mathrm{ml}$ and lowest concentration of $0.125 \mathrm{mg} / \mathrm{ml}$ gave the highest mortality of $72 \%$ and the lowest mortality of $28 \%$ after 24 hours. The values increased up to $80 \%$ and $32 \%$ after 48 hours. For 72 hours, the final values recorded were $84 \%$ and $40 \%$. The $\mathrm{LC}_{50}$ values from probit and logit analysis were $0.851,0.609$ and 0.337 for 24,48 and 72 hours (Table 3).

Larvicidal potential of bakain (Melia azedarach) against $3^{\text {rd }}$ instar larvae of Plutella xylostella: The toxicity of bakain plant extract against $3^{\text {rd }}$ instar larvae of $P$. xylostella exhibited that bakain plant extract was effective against $3^{\text {rd }}$ instar larvae of $P$. xylostella at different time intervals showing the highest mortality of $68 \%$ with $40 \mathrm{mg} / \mathrm{ml}$ and the lowest mortality of $24 \%$ after 24 hours. For 48 hours, the bakain plant extract showed $76 \%$ and $28 \%$ mortalities. The mortality values were increased up to $84 \%$ and $40 \%$ after 72 hours. The $\mathrm{LC}_{50}$ values for different time intervals of 24,48 and 72 hours were $17.654,11.857$ and 6.746 respectively (Table 2).

The toxicity of bakain enhanced silver nanoparticles against $3^{\text {rd }}$ instar larvae of $P$. xylostella. The application of bakain silver nanoparticles against $3^{\text {rd }}$ instar larvae of P. xylostella after 24 hours showed the highest mortality of $72 \%$ at the concentration limit of $4 \mathrm{mg} / \mathrm{ml}$ and the lowest $28 \%$ mortality at the concentration of 0.25 $\mathrm{mg} / \mathrm{ml}$. For 48 hours and 72 hours, the values of the 
highest and lowest mortalities were $80 \%, 32 \%$ and $88 \%$, $44 \%$ respectively. The $\mathrm{LC}_{50}$ values for 24,48 and 72 hours were 1.565, 1.029 and 0.532 (in $\mathrm{mg} / \mathrm{ml}$ ) respectively (Table 3).

Larvicidal potential of bitter gourd (Momordica charantia) against $3^{\text {rd }}$ instar larvae of Plutella xylostella: The results of present studies have shown that the plant extract of bitter gourd was found to be toxic against $3^{\text {rd }}$ instar larvae of P. xylostella at different time intervals. The $68 \%$ and $24 \%$ mortality values recorded after 24 hours at the concentration limits of 30 $\mathrm{mg} / \mathrm{ml}$ and $1.875 \mathrm{mg} / \mathrm{ml}$. The per cent mortalities were 72 at high concentration and 28 at lower limit of concentration after 48 hours. The final values obtained after 72 hours were $80 \%$ and $32 \%$ respectively. The major variations in $\mathrm{LC}_{50}$ values recorded after 24,48 and 72 hours were $15.095,11.715$ and 8.683 respectively (Table 2).

The toxicity of bitter gourd nanoparticles was the most effective when applied to the $3^{\text {rd }}$ larval instar of $P$. xylostella. For 24 hours, the highest concentration 3 $\mathrm{mg} / \mathrm{ml}$ showed $72 \%$ mortality and lowest concentration of $0.1875 \mathrm{mg} / \mathrm{ml}$ showed $24 \%$ mortality. The final values at the maximum and minimum concentrations of bitter gourd silver nanoparticles were $75 \%, 32 \%$ and $84 \%$, $36 \%$ after 24 hours and 72 hours respectively. The $\mathrm{LC}_{50}$ values were $1.324,0.951$ and 0.639 (in $\mathrm{mg} / \mathrm{ml}$ ) respectively for different time of intervals (Table 3).

Larvicidal potential of eucalyptus (Eucalyptus camaldulensis) against $3^{\text {rd }}$ instar larvae of Plutella xylostella: Results of eucalyptus plant extract against $3^{\text {rd }}$ instar larvae of $P$. xylostella showed promising effects with exposure to different concentrations at 24 hours with highest per cent mortality up to $64 \%$. The bar for the lowest concentration was set at $24 \%$. At the 48 hour interval only a $4 \%$ increase in mortality was observed for the lowest concentration whereas the increase was double (8\%) for the highest concentration of $30 \mathrm{mg} / \mathrm{ml}$. The reverse was observed at the last 72 hours observation where the increase in per cent mortality was $4 \%$ for $1.875 \mathrm{mg} / \mathrm{ml}$ concentration and $8 \%$ for 30 $\mathrm{mg} / \mathrm{ml}$ concentration. The $\mathrm{LC}_{50}$ values observed were $16.126,11.172$, and $6.542 \mathrm{mg} / \mathrm{ml}$ for 24,48 , and 72 hours observations respectively (Table 2).

For the Ag-nanoparticles of eucalyptus, 4\% increase in mortality was recorded for both $0.1875 \mathrm{mg} / \mathrm{ml}$ and 3 $\mathrm{mg} / \mathrm{ml}$ concentrations as compared to the ethanol-based plant extracts and the values were $28 \%$ and $68 \%$ respectively after 24 hours. For 48 hours interval, 32\% mortality was the lowest with $3 \mathrm{mg} / \mathrm{ml}$. Minimum concentration of $0.1875 \mathrm{mg} / \mathrm{ml}$ gave $44 \%$ mortality for after 72 hour observation and $3 \mathrm{mg} / \mathrm{ml}$ concentration was recorded much higher at $80 \%$ killing 20 out of $25 P$. xylostella larvae in the petri dish. The $\mathrm{LC}_{50}$ values for this experiment were 1.367, 0.951 , and $0.514 \mathrm{mg} / \mathrm{ml}$ for 24 , 48, and 72 hours' observations respectively (Table 3 ).

Larvicidal potential of garlic (Allium sativum) against $3^{\text {rd }}$ instar larvae of Plutella xylostella: Regarding the results of Allium sativum, the per cent mortality observed at the 24 hours was $20 \%$ at the concentration limit of $1.4375 \mathrm{mg} / \mathrm{ml}$ and $68 \%$ at 23 $\mathrm{mg} / \mathrm{ml}$. There was no death in the control populations and therefore no reason to calculate the corrected mortality values. The per cent mortality increased to $24 \%$ and $76 \%$ at the 48 hours interval respectively. Final observed values noted were $32 \%$ and $80 \%$ for the highest and lowest concentrations at the 72 hours mark. The lethal concentration values for $50 \%$ of the population were calculated via probit analysis as 12.135 , 9.237, and $6.689 \mathrm{mg} / \mathrm{ml}$ for the 24, 48, and 72 hours marks respectively (Table 2).

Regarding the silver-nanoparticles of garlic, the observed results for per cent mortality were $24 \%$ and $72 \%$ for lowest and highest concentrations at the 24 hours interval. For the 48 hours mark, an increase of $8 \%$ was observed for highest concentration of $23 \mathrm{mg} / \mathrm{ml}$, making its mortality equal to $80 \%$. The lowest concentration only saw an increase of $4 \%$ i.e. at $28 \%$. For the final 72 hours mark, the observed per cent mortality values for lowest concentration and highest concentration were $36 \%$ and $84 \%$ respectively. The $\mathrm{LC}_{50}$ values calculated via probit analysis were 1.156, 0.902, and $0.729 \mathrm{mg} / \mathrm{ml}$ for the 24,48 , and 72 hours marks respectively (Table 3 ).

\section{DISCUSSION}

The present investigation suggests the potential of plant species in controlling diamondback moth. Garlic ethanolic extract gave good control against diamondback moth. Garlic has well been reported to contain pesticidal properties. Zehnder and Griggs (1996) described that garlic gave effective control of the caterpillars on lettuce and cabbage. The authors applied garlic oil as sprays which killed aphids, cabbage loopers, earwigs, june bugs, leafhoppers, squash bugs and white flies. Similar results have also been reported by Reuben et al. (2006) who used garlic extract to control larval instar of 
diamondback moth.

The present study revealed that Zingiber officinale ethanolic extracts gave the lowest $\mathrm{LC}_{50}$ value of 12.701 $\mathrm{mg} / \mathrm{ml}$ after $24 \mathrm{~h}$ and after increase of time the percent mortality increased and the $\mathrm{LC}_{50}$ values decreased. This show the toxicity of ginger extract as the value of $\mathrm{LC}_{50}$ decreased down to $5.704 \mathrm{mg} / \mathrm{ml}$ after $72 \mathrm{~h}$. The results had some resemblance with those of Babu et al. (2018) because in the present study we used the ethanol for the extraction instead of aceton.

Similarly, the extracts of datura affected the activity of larval instars of P. xylostella throughout the experiment conducted in the laboratory. The results are in line with those reported by Mari (2012). The researcher proved that the datura plant extract are cheap and effective for the control of insect pests. Likewise, neem extract was also found effective against the pest. Neem extract slightly increased the death of larvae of P. xylostella. Similar results were also reported by Mari (2012) when neem extract was applied on $2^{\text {nd }}$ and $3^{\text {rd }}$ instar larvae of P. xylostella.

The present study indicated that the botanical insecticides have good toxic effect against the $3^{\text {rd }}$ instar larvae of diamondback moth. The different plants extract i.e. ginger, neem, clove and bitter gourd had great potential to kill the maximum population of diamondback moth at high concentration. All these plants extract gave more than $80 \%$ mortality which was highest percentage mortality at the rate of 23, 24, 20 and $30 \mathrm{mg} / \mathrm{ml}$ respectively after 72 hour interval. These results are mostly similar with the those of Abbasipour et al. (2010) who reported that extract of Peganum harmala were toxic against the larvae of diamondback moth.

The silver nanoparticles studied here were synthesized using a botanical byproduct. Notably, neem cakesynthesized silver nanoparticles were extremely effective against $P$. xylostella. Neem cake-synthesized AgNP were extremely toxic and the $\mathrm{LC}_{50}$ value was 0.611 $\mathrm{mg} / \mathrm{ml}$ which was lowest value and killed 92 percent population of $3^{\text {rd }}$ larval instar of diamondback moth. The results are in line with the finding of Chandramohan et al. (2016) against larvae and pupae of the dengue vector Aedes aegypti.

Synthesized silver nanoparticles blended with datura extracts applied on $3^{\text {rd }}$ instar larvae of diamondback moth showed 84 percent mortality at the rate of 2 $\mathrm{mg} / \mathrm{ml}$. These results are in agreement with those of
Murugan et al. (2015) against malaria mosquitoes.

It was practical that plant extracts can be successfully used as an excellent substitute to synthetic insecticides. Further studies are essential to discover the required lower application rates and extraction methods that will provide a more effective control of diamondback moth to economic threshold levels.

Authors' contribution: FA, MT and FAS conceived the idea, FA conducted the research trials; ZRM and TZ helped in the preparation of nanoparticles; MT performed the statistical analysis; FA wrote the manuscript; All the authors reviewed and edited the manuscript.

Conflict of interest: The authors declare no conflict of interest.

\section{REFERENCES}

Abbasipour, H., Mahmoudvand, M., Rastegar, F., Basij, M., 2010. Insecticidal activity of Peganum harmala seed extract against the diamondback moth, Plutella xylostella. Bulletin of Insectology 63, 259263.

Ahmad, N., Ansari, M.S., Hasan, F., 2012. Effects of neem based insecticides on Plutella xylostella L. Crop Protection 34, 18-24.

Ahmed, S., Grainge, M., Hylin, J., Mitchell, W., Litsinger, J., 1984. Some promising plant species for use as pest control agents under traditional farming systems. Schriftenreihe der Gesellschaft fur Technische Zusammenarbeit 1, 565-580.

Babu, G.K., Dolma, S.K., Sharma, M., Reddy, S.E., 2018. Chemical composition of essential oil and oleoresins of Zingiber officinale and toxicity of extracts/essential oil against diamondback moth (Plutella xylostella). Toxin Reviews, 1-10.

Benelli, G., 2016. Green synthesized nanoparticles in the fight against mosquito-borne diseases and cancer a brief review. Enzyme and Microbial Technology 95, 58-68.

Bullangpoti, V., Wajnberg, E., Audant, P., Feyereisen, R., 2012. Antifeedant activity of Jatropha gossypifolia and Melia azedarach senescent leaf extracts on Spodoptera frugiperda (Lepidoptera: Noctuidae) and their potential use as synergists. Pest Management Science 68, 1255-1264.

Chandramohan, B., Murugan, K., Panneerselvam, C., Madhiyazhagan, P., Chandirasekar, R., Dinesh, D., Rajaganesh, R., 2016. Characterization and mosquitocidal potential of neem cake-synthesized 
silver nanoparticles: genotoxicity and impact on predation efficiency of mosquito natural enemies. Parasitology Research 115, 1015-1025.

El-Bokl, M.M., 2016. Toxicity and bio efficacy of selected plant extracts against the mosquito vector Culexpipiens L. (Diptera: Culicidae). Enviornment $6,7$.

Furlong, M.J., Wright, D.J., Dosdall, L.M., 2013. Diamondback moth ecology and management: problems, progress, and prospects. Annual Review of Entomology 58, 517-541. .

Grzywacz, D., Rossbach, A., Rauf, A., Russell, D.A., Srinivasan, R., Shelton, A.M., 2010. Current control methods for diamondback moth and other brassica insect pests and the prospects for improved management with lepidopteronresistant BT vegetable brassicas in Asia and Africa. Crop Protection 29, 68-79.

Isman, M.B., 1999. Neem and related natural products. Biopesticides, 139-153.

Jacobson, M., 1989. Focus on Biochemical Pesticides. .Journal of Botany 1, 45-50.

Li, S., Deng, W., Zhang, Q., 2001. The killing action and growth influence of Momordica charantia extracts on Liriomyza sativae. Journal Huazhong (Central China) Agricultural University 20, 539-543.

Li, Z., Feng, X., Liu, S.S., You, M., Furlong, M.J., 2016. Biology, ecology, and management of the diamondback moth in China. Annual Review of Entomology 61, 277-296.

Loc, H., Srinivasa, N., Girish, R., 2014. Biological activity of Datura metel on diamondback moth, Plutella xylostella L. infesting brassicaceous vegetables. International Journal of Plant Protection 7, 1-8.

Mari, J.M., 2012. Efficacy of different plant extracts against diamondback moth, Plutella xylostella (L.) on cauliflower, International Conference on Applied Life Sciences.

Murugan, K., Dinesh, D., Kumar, P.J., Panneerselvam, C., Subramaniam, J., Madhiyazhagan, P., Higuchi, A., 2015. Datura metel-synthesized silver nanoparticles magnify predation of dragonfly nymphs against the malaria vector Anopheles stephensi. Parasitology Research 114, 4645-4654.

Parashar, U.K., Saxena, P.S., Srivastava, A., 2009. Bioinspired synthesis of silver nanoparticles Digest Journal of Nanomaterials \& Biostructures 4.

Patil, R.H., Shaila, H.M., Awaknavar, J.S., 2017. Management of diamondback moth, Plutella xylostella L. through biorationals in cabbage. Mysore Journal of Agricultural Sciences, 1, 148152.

Rembold, H., 1989. Isomeric Azadirachtins and their mode of action. Focus on Phytochemical Pesticides 1, 47-67.

Reuben, S.O., Yahya, S.N., Misangu, R.N., Mulungu, L.S., 2006. Field evaluation on effects of common spices in the control of diamondback moth (Plutella xylostella L.) pest of Chinese cabbage (Brassica campestris L.) commercial cultivar. Asian Journal of Plant Sciences 5, 85-90.

Sarker, P., Rahman, M., Das, B., 2007. Effect of intercropping with mustard with onion and garlic on aphid population and yield. Journal of BioScience 15, 35-40.

Sayyed, A.H., Omar, D., Wright, D.J., 2004. Genetics of spinosad resistance in a multi-resistant fieldselected population of Plutella xylostella. Pest Management Science 60, 827-832.

Schmutterer, H., 1990. Properties and potential of natural pesticides from the neem tree, Azadirachta indica. Annual Review of Entomology 35, 271-297.

Shelton, A.M., Nault, B.A., 2004. Dead-end trap cropping: a technique to improve management of the diamondback moth, Plutella xylostella (Lepidoptera: Plutellidae). Crop Protection 23, 497-503.

Zehnder, G., Griggs, T., 1996. Organic insecticides not as effective as synthetics but still useful for vegetable insect control Highlights Agricultural Research 43, 16-18. 